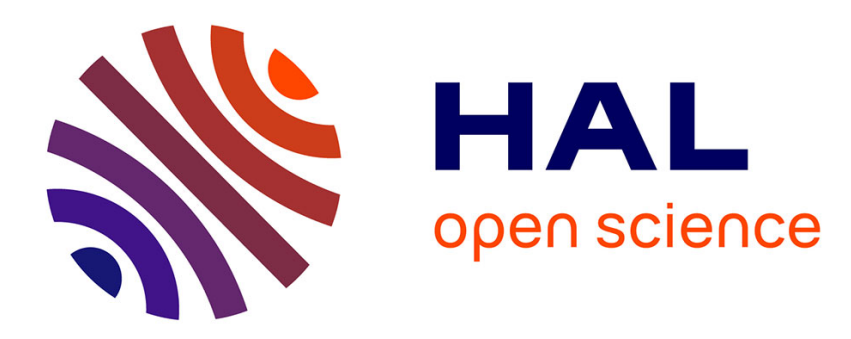

\title{
Laser monitoring system for the ATLAS tile calorimeter
} S. Viret

\section{To cite this version:}

S. Viret. Laser monitoring system for the ATLAS tile calorimeter. 11th Pisa Meeting on Advanced Detectors, May 2009, la Biodola, Italy. pp.120-122. in2p3-00461504

\section{HAL Id: in2p3-00461504 https://hal.in2p3.fr/in2p3-00461504}

Submitted on 4 Mar 2010

HAL is a multi-disciplinary open access archive for the deposit and dissemination of scientific research documents, whether they are published or not. The documents may come from teaching and research institutions in France or abroad, or from public or private research centers.
L'archive ouverte pluridisciplinaire HAL, est destinée au dépôt et à la diffusion de documents scientifiques de niveau recherche, publiés ou non, émanant des établissements d'enseignement et de recherche français ou étrangers, des laboratoires publics ou privés. 


\title{
LASER Monitoring system for the ATLAS Tile Calorimeter
}

\author{
S. Viret ${ }^{\mathrm{a}}$, for the LPC ATLAS group \\ ${ }^{a}$ Laboratoire de Physique Corpusculaire (CNRS/IN2P3), Clermont-Ferrand, France
}

\begin{abstract}
The ATLAS detector at the Large Hadron Collider (LHC) at CERN uses a scintillator-iron technique for its hadronic Tile Calorimeter (TileCal). Scintillating light is readout via 9852 photomultiplier tubes (PMTs). Calibration and monitoring of these PMTs are made using a LASER based system. Short light pulses are sent simultaneously into all the TileCal photomultiplier's tubes (PMTs) during ATLAS physics runs, thus providing essential information for ATLAS data quality and monitoring analyses. The experimental setup developed for this purpose is described, as well as preliminary results obtained during ATLAS commissioning phase in 2008.
\end{abstract}

Key words: LHC, ATLAS, Tile Calorimeter, LASER, Calibration PACS: $29.40 . \mathrm{Vj}$

\section{Introduction}

LASER monitoring system [1] is an important part of the ATLAS TileCal [2] calibration scheme. Its main role is to measure the stability and the linearity of the 9852 PMTs used in the detector. This will be of particular importance during physics analysis, as energy resolution will strongly depend on our understanding of the PMT response. The LASER system setup is presented in Section 2, and some first results and achievements obtained during TileCal commissioning are presented in Section 3. Conclusions are given in Section 4.

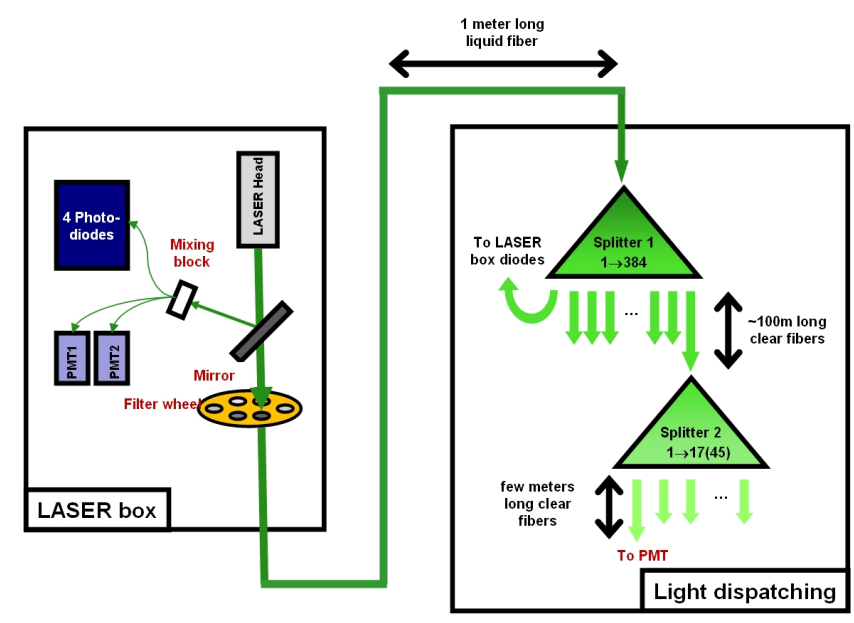

Figure 1: Light path: from the LASER to the TileCal channels

\section{LASER System Description}

\subsection{Hardware setup}

LASER monitoring system was initially proposed in Ref. [3]. The idea is to send short LASER pulses to the TileCal PMTs. Light pulses give a similar PMT response than a signal produced by a particle. The major difference is that the initial energy, in the case of the LASER pulse, is known precisely. This thus allows to monitor accurately PMTs gains and linearity.

However, illuminating simultaneously 9852 PMTs requires a powerful light source. Pulse shape requirements $(\sim 10 \mathrm{~ns}$ pulse width) has driven our choice toward a commercial Q-switched DPSS (Diode-Pumped Solid State) LASER manufactured by SPECTRA-PHYSICS [4]. This is a frequency-doubled infrared LASER emitting a $532 \mathrm{~nm}$ green light beam ${ }^{1}$. This LASER is the first part of a setup described on Fig. 1. It is divided into two distinct parts: the LASER box and the light dispatching system.

LASER box is the main component of the system, as it provides its absolute calibration and triggering tools. A part of the light emitted by the LASER head is indeed collected there and sent to one photodiode and two PMTs (identical to the TileCal PMTs). The photodiode is used for the absolute calibration of the system, and the PMTs for the triggering of the LASER events. In order to monitor light budget at different levels, three other diodes are collecting light emitted after the first beam splitter. The four photodiodes, which are contained into the same thermally-regulated box, are then inter-calibrated using an ${ }^{241} \mathrm{Am}$ radioactive source. The LASER box also contains a rotating filter wheel, which is used to attenuate the

\footnotetext{
${ }^{1}$ This wavelength is close to the one of the light produced in the scintillating tiles $(480 \mathrm{~nm})$
} 
outgoing light in order to cover the whole TileCal dynamic (from $100 \mathrm{MeV} / \mathrm{PMT}$ to $1.5 \mathrm{TeV} / \mathrm{PMT}$ ).

Then, the light outgoing the LASER box is brought via a $1 \mathrm{~m}$ long liquid fiber towards a first beam-splitter. This splitter dispatches the primary beam toward a bunch of $\sim 400$ clear fibres. In order to improve the splitting uniformity, the amount of light going out of the secondary fibres is tunable via dedicated connectors. Long clear fibers then bring the light from the counting rooms (where the main system stands) to TileCal modules. The light finally enters the modules where it is split a last time before reaching the PMTs.

\subsection{Electronics and software aspects}

The system is monitored, controlled, and if necessary interlocked, by a set of 6 electronic cards located in a VME crate situated right below the LASER box. This is also where the timing of the LASER pulses is handled. Indeed, LASER event are taken within ATLAS normal physics run, during the $3 \mu \mathrm{s}$ gap occurring at the end of each LHC cycle. The timeline of a LASER calibration pulse is sketched on Fig. 2.

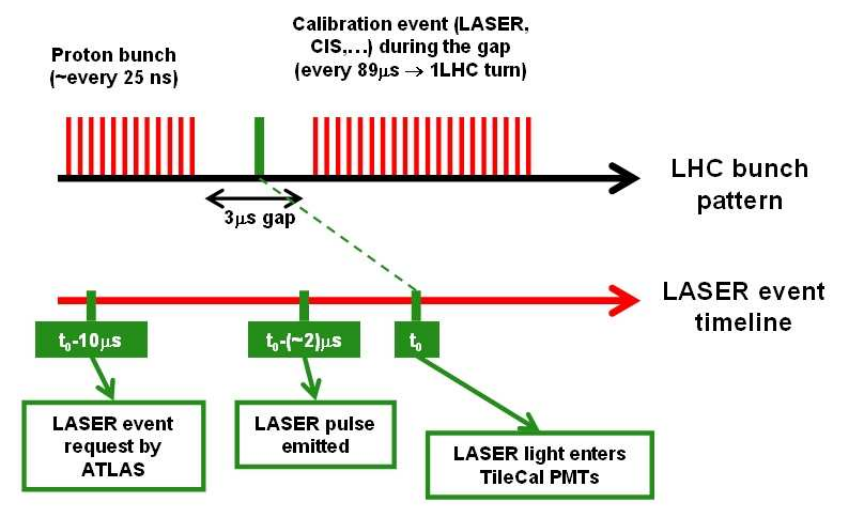

Figure 2: The timeline of a LASER calibration pulse

The interface between ATLAS and LASER hardware is made via a dedicated low-level software called Lutin. This program, which runs in the VME crate on a special CPU, is a generic interface. It thus enables not only the LASER system control from ATLAS, but also allows an independent access to the system (via a special program named LasCo), an interface to the ATLAS DCS (Detector Control System),...

\section{Preliminary results}

As previously stated, the LASER system main goal is to control and monitor the PMTs linearity and stability. The chosen solution, which is sketched on Fig. 3 is to compare the PMT signal to the diodes signals, as this one is precisely known and calibrated for every pulse.

The first results on stability, obtained with calibration runs taken during late 2008 (ATLAS was working in stable mode

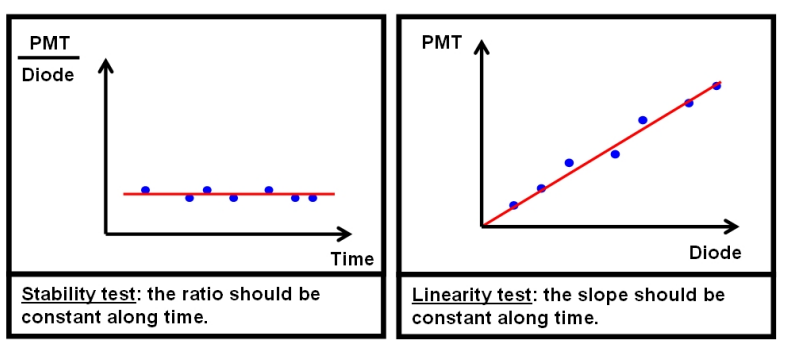

Figure 3: How linearity and stability are tested with the LASER system ?

then), have shown that PMTs relative stability over 100 days was better than $1 \%$ for most of the channels. Analyses are still ongoing in order to improve those results. The linearity tests are more sensitive to the system intrinsic stability, and we are currently working on possible technical improvements in order to fulfill the necessary requirements for those tests.

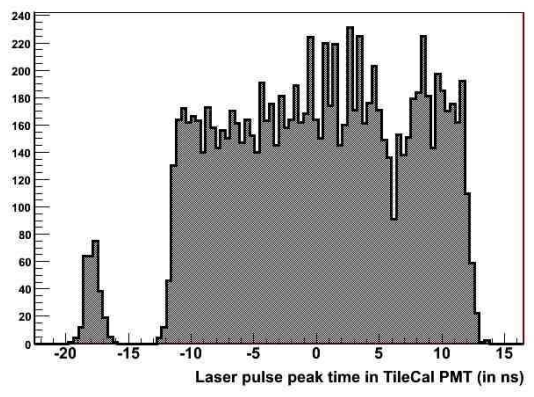

Figure 4: Difference between the LASER pulse peak time in one of the TileCal PMT and the time requested

It has also been clearly demonstrated (see Fig. 4) that the timing of the LASER pulses is well within requirements, and that the system is able to send light into the TileCal with a $\pm 25 n s$ precision (to be compared with the gap width of $3 \mu \mathrm{s}$ ).

\section{Conclusions}

A system to monitor the linearity and stability of the ATLAS TileCal 9852 PMTs has been described. This calibration setup is based on high intensity LASER pulses sent via an optic fibers network trough the PMTs within ATLAS physics run. The light intensity is precisely measured using calibrated photodiodes, and the monitoring procedure is based on the comparison of the diodes signals with the PMTs ones. The system is now fully integrated into ATLAS calibration scheme, and first encouraging results have been obtained.

\section{References}

[1] http://atlas-tile-laser.web.cern.ch/

[2] J. Abdallah et al. - "Design, Construction and Installation of the ATLAS Hadronic Barrel Scintillator-Tile Calorimeter" - ATL-TILECAL-PUB2008-001

[3] Z. Ajaltouni et al. - "The Tilecal laser monitoring" - ATL-TILECAL-94039

[4] http://www.newport.com/ 